\title{
PENERAPAN ISAK 35 PADA MASJID BAITUL HIDAYAH PUGER JEMBER
}

\author{
Ismi Darojatul Ula, Moh Halim, Ari Sita Nastiti \\ Universitas Muhammadiyah Jember \\ Jember, Indonesia \\ Ismiula19@gmail.com
}

\begin{abstract}
ABSTRAK
The purpose of this study was to determine the suitability of financial statements according to ISAK No. 35 and how the accounting record in the financial statements of Baitul Hidayah Puger Mosque with generally accepted accounting principles. The research was conducted at the Baitul Hidayah Puger Mosque using data collection techniques with interviews and documentation. The data analysis technique in this research was a qualitative descriptive analysis where the data was compiled and described based on the result of data collection on financial statements, then was compared with relevant theories to the problem, which could then be drawn a conclusion. Based on the result of the study, it could be concluded that the basis of recording applied at the Baitul Hidayah Puger Mosque was incomplete and not sequential according to applicable standards. The financial statements that made a report, a report on changes in net assets, a cash flow statements and notes on financial statements. Implementation of ISAK No. 35 Baitul Hidayah Puger Mosque was not in accordance with generally accepted accounting principles. The financial reporting of the Baitul Hidayah Mosque in Puger was not in accepted accounting principles.
\end{abstract}

Kata Kunci: ISAK No. 35, Mosque, Nonlaba.

\section{PENDAHULUAN}

Masjid adalah tempat ibadah umat muslim. Masjid juga memiliki peran sebagai tempat melakukan berbagai akivitas keagamaan bagi umat Islam. Apakah itu peringatan hari besar umat Islam, maulidan atau tempat pengajaran agama Islam lainnya. Bahkan zaman Rasullah SAW Masjid bukan hanya untuk pengajaran agama Islam tapi berkaitan juga dengan politik dan stategi perang. Masjid merupakan salah satu organisasi sektor publik yang tergolong dalam organisasi nonlaba (non profit oriented) yang dalam menjalankan aktivitasnya, dengan mengelola sumber daya yang dimilikinya dan sumber daya yang diperoleh dari masyarakat secara sukarela dan ikhlas. Menurut Dewan Masjid Indonesia (DMI) terdapat tiga fungsi Masjid. Pertama, Masjid sebagai ibadah (mdlahah) juga merupakan tempat ibadah secara luas (ghairu madhlah) selama dilakukan dalam batas-batas syariah. Kedua, Masjid sebagai wadah pengembangan masyarakat melalui berbagai sarana dan prasarana yang dimiliki Masjid yang bersangkutan. Ketiga, Masjid sebagai pusat komunikasi dan persatuan umat (Gazalba, sidi (1994) ) 
Masjid merupakan salah satu jenis organisasi nirlaba dalam bidang keagamaan. Pada organisasi nirlaba cenderung tidak ada suatu kepemilikan organisasi yang mutlak, karena biasanya organisasi nirlaba ini di dirikan oleh beberapa orang maupun kelompok. Modal untuk mendirikan organisasi nirlaba ini juga bisa di dapatkan melalui hutang. Sedangkan untuk kebutuhan operasional nya bisa di dapatkan dari pendapatan atau jasa yang di berikan. Namun hal ini berakibat pengukuran jumlah dan kepastian arus kas masuk menjadi ukuran yang penting bagi para pemakai dari laporan keuangan masjid tersebut.

Laporan keuangan organisasi nonlaba meliputi laporan posisi keuangan pada akhir periode, laporan penghasilan komprehensif, laporan perubahan aset neto, laporan arus kas untuk suatu periode pelaporan, dan catatan atas laporan keuangan.

Oleh karena itu, pembuatan laporan keuangan masjid sangat penting karena dari laporan keuangan tersebut akan menampilkan dan menunjukkan bagaimana pengelolaan keuangan yang telah dilakukan.

Berdasarkan latar belakang yang dipaparkan diatas, maka peneliti tertarik untuk melakukan penelitian yang bejudul
“Penerapan ISAK 35 Pada Masjid Baitul Hidayah Puger Jember".

\section{METODE PENELITIAN}

\section{Jenis Penelitian}

Jenis penelitian yang digunakan adalah kualitatif deskriptif yaitu penelitian yang bertujuan menjelaskan makna dibalik realita sosial yang terjadi. Penelitian kualitatif bermaksud untuk memahami fenomena tentang apa yang dialami oleh subjek penelitian misalnya perilaku, persepsi, motivasi, tindakan dan lain sebagainya (Moelong, 2014)

Metode penelitian yang digunakan yaitu metode kualitatif deskriptif digunakan karena penelitian ini memberikan gambaran tentang wujud pengelolaan keuangan yang sesuai dengan standar akuntansi yaitu ISAK No. 35 pada masjid. Dikarenakan metode menggunakan kualitatif deskriptif maka dalam langkah penelitiannya tidak perlu merumuskan hipotesis.

\section{Jenis dan Sumber Data}

Penelitian ini menggunakan data kualitatif berupa keterangan-keterangan yang diberikan baik secara lisan maupun tulisan serta dokumen-dokumen dan hasil yang dilakukan peneliti.

Sedangkan data yang digunakan dalam penelitian ini antara lain 
1. Data primer

Data Primer adalah data pertama kali yang dikumpulkan oleh peneliti melalui upaya pengambilan data di lapangan langsung. Atau data yang diperoleh langsung dari sumbernya melalui wawancara dan observasi langsung di lapangan baik secara terstruktur maupun tidak terstruktur. Wawancara merupakan sumber bukti yang esensial bagi penelitian kualitatif Yin, (2013:108). Wawancara dilakukan peneliti kepada pihak takmir, bendahara masjid Baitul Hidayah Puger dan kepada masyarakat sekitar.

2. Data sekunder

Merupakan data yang didapatkan tidak secara langsung dari objek atau subjek penelitian. Atau data yang diperoleh dari sumber kedua dari data yang tau peneliti dengan informan tidak terjadi hubungan secara langsung melainkan peneliti mengambil data dari peneliti lainnya. Data sekunder dalam penelitian ini berupa dokumen-dokumen yang bersal dari buku, pedoman, jurnal, internet (website), peraturan perundangundangan, laporan keuangan, dan lain sebagainya.

\section{Metode Pengumpulan Data}

1. Wawancara

Menurut Moleong (2012:186) wawancara adalah percakapan dengan maksud tertentu. Percakapan dilakukan oleh dua pihak, yaitu pewawancara yang mengajukan pertanyaan dan terwawancara yang memberikan jawaban atas pertanyaan itu.

\section{Dokumentasi}

Menurut Arikunto (2002), metode dokumentasi adalah metode mencari data mengenai hal-hal yang berupa catatan, transkip, buku, surat kabar, majalah, prasasti, agenda, foto-foto kegiatan. Metode dokumentasi dalam penelitian ini dipergunakan untuk melengkapi data dari hasil wawancara dan hasil pengamatan.

3. Obsevasi atau pengamatan langsung Seperti disebutkan Creswell (2016: 254), Observasi kualitatif yakni ketika peneliti turun langsung ke lapangan guna mengamati perilaku dan aktivitas individu-individu yang terdapat di lokasi penelitian.

\section{Teknik Analisis Data}

1. Langkah pertama adalah menyiapkan data-data empiris hasil dari pengamatan yang sudah dilakukan peneliti.

2. Langkah kedua adalah menjelaskan prosedur pengelolaan keuangan pada Masjid Baitul Hidayah

3. Langkah ketiga yaitu menghubungan dengan teori-teori yang ada di pembahasan bab II 
4. Langkah keempat, hasil jawaban dari langkah ketiga dikonstruk dengan ISAK No. 35 tentang Pelaporan Keuangan Nonlaba

5. Langkah kelima, menarik kesimpulan.

\section{HASIL PENELITIAN}

\section{Deskripsi Objek Penelitian}

Masjid Baitul Hidayah Puger yang menjadi objek dalam penelitian ini merupakan masjid yang berdomisili di Desa Mojosari RT 002/RW 019 Kecamatan Puger Kabupaten Jember. Masjid Baitul Hidayah Puger didirikan pada tahun 1978. Bangunan masjid ini berdiri di tanah wakaf Kyai Husein yang merupakan ayah dari Bapak Wahid Kyai Husein ini adalah orang pertama yang menjadi pendakwah di masjid baitul hidayah ini tetapi beliau sudah wafat, dan sekarang diteruskan oleh anaknya yaitu Bapak Wahid.

Pembangunan masjid ini dilakukan selama satu tahun yang melibatkan banyak orang khususnya masyarakat sekitar atau warga puger. Pembangunan ini banyak mengeluarkan dana yang tidak sedikit, karena banyak tenaga ahli yang terlibat dalam pembangunan masjid tersebut. Biaya untuk membangun masjid ini diperoleh dari donasi, sumbangan dan infaq hari jumat.
Pada awalnya pembangunan masjid ini sangat megah untuk sekelas masjid yang berada di puger bentuk bangungan masjid keseluruhan masih terjaga keaslinya akan tetapi ada beberapa bagian masjid yang mengalami perubahan (perenovasian).

Masjid ini mengalami beberapa kali peronovasian di mulai dari tahun 1999, yang mana pada tahun ini dilakukan perenovasian seperti membangun pagar dan lain sebagainya. Pada tahun 2020 yakni tahun lalu dilakukan perenovasian untuk memperluas masjid ditambah menjadi dua kali lipat kebelakang.

\section{Profil Masjid Baitul Hidayah}

Masjid merupakan tempat ibadah bagi umat islam di dunia. Selain digunakan sebagai tempat ibadah, masjid juga merupakan salah satu unsur penting dalam struktur masyarakat islam.

Setiap masjid memiliki sejarah masing-masing dengan latar belakang yang berbeda-beda. Perbedaan latar belakang tersebut menjadi nilai tersendiri bagi masing-masing masjid. Salah satunya Masjid Baitul Hidayah Puger yang memiliki sejarah seperti yang telah dijelaskan pada subab sebelumnya. 


\section{Pencatatan Akuntansi di Masjid Baitul}

\section{Hidayah Puger Jember}

Berdasarkan hasil observasi pada pengelola Masjid Baitul Hidayah, pencatatan administrasi keuangan dibedakan menjadi dua yaitu penerimaan dan pengeluaran. Sumberdaya yang diterima kemudian dilaporkan dan dikelola oleh Pengelola Masjid Baitul Hidayah untuk membiayai belanja renovasi. Penerimaan Pengelola Masjid Baitul Hidayah yaitu bersumber dari infaq. Infaq yang terkumpul dihitung setiap hari Jum'at oleh majelis yang bertugas dan dicatat jumlahnya. Setiap penerimaan yang diterima oleh bendahara akan dicatat. Pengeluaran Masjid Baitul Hidayah yaitu pengeluaran untuk renovasi Masjid.

\section{Deskripsi Laporan Keuangan Masjid Baitul Hidayah}

Laporan keuangan Masjid Baitul Hidayah dibuat oleh bendahara masjid. Laporan keuangan disusun dalam periode mingguan. Laporan keuangan Masjid Baitul Hidayah sangat erat hubungannya dengan proses pencatatan transaksi yang dilakukan yang berhubungan dengan penerimaan dan pengeluaran kas. Proses pencatatan dilakukan mulai diterimanya dana yang berasal dari infaq. Proses pengeluaran kas yang berawal dari permintaan dana yang dibuktikan dengan nota yang diajukan kepada bendahara, yang selanjutnya bendahara akan membuat laporan keuangan setiap minggunya

Tabel 1. Buku Kas Mingguan Takmir Masjid Baitul Hidayah Tahun 2020

\begin{tabular}{|c|c|c|c|c|}
\hline Tanggal & Uraian & Masuk (Rp) & Keluar (Rp) & Saldo \\
\hline 03-Jan-2020 & Infaq jumat pon & 800.000 & & 263.412 .000 \\
\hline 10-Jan-2020 & Infaq jumat kliwon & 240.000 & & 263.652 .000 \\
\hline 31-Jan-2020 & Infaq jumat legi & 3.050 .000 & & 266.702 .000 \\
\hline 06-Feb-2020 & Infaq jumat legi & 1.735 .000 & & 268.437 .000 \\
\hline 20-Mar-2020 & Infaq jumat kliwon & 670.000 & & 269.107 .000 \\
\hline 04-Mar-2020 & Infaq jumat wage & 390.000 & & 269.497 .000 \\
\hline 10-Apr-2020 & Infaq jumat legi & 190.000 & & 269.687 .000 \\
\hline 16-Apr-2020 & Infaq jumat pon & 247.000 & & 269.934 .000 \\
\hline 24-Apr-2020 & Infaq jumat kliwon & 225.000 & & 270.159 .000 \\
\hline 08-Mei-2020 & Infaq jumat wage & 455.000 & & 270.614 .000 \\
\hline 15-Mei-2020 & Infaq jumat legi & 800.000 & & 271.414 .000 \\
\hline \multirow[t]{2}{*}{ 22-Mei-2020 } & Infaq jumat pon & 356.000 & & 271.770 .000 \\
\hline & idul fitri & 10.980 .000 & & 282.750 .000 \\
\hline 29-Mei-2020 & Infaq jumat kliwon & 1.025 .000 & & 283.775 .000 \\
\hline 05-Juni-2020 & Infaq jumat paing & 420.000 & & 284.195 .000 \\
\hline 12-Juni-2020 & Infaq jumat wage & 230.000 & & 284.425 .000 \\
\hline 19-Juni-2020 & Infaq jumat legi & 1.426 .000 & & 285.851 .000 \\
\hline 26-Juni-2020 & Infaq jumat pon & 270.000 & & 286.121 .000 \\
\hline 03-Juli-2020 & Infaq jumat kliwon & 4.546 .000 & & 290.667 .000 \\
\hline 10-Juli-2020 & Infaq jumat paing & 1.425 .000 & & 292.092 .000 \\
\hline 17-Juli-2020 & Infaq jumat wage & 10.294 .000 & & 302.386 .000 \\
\hline
\end{tabular}




\begin{tabular}{|c|c|c|c|c|}
\hline & pengembalian dana simpan & 1.908 .000 & & 304.294 .000 \\
\hline & material (batu dan koral) & & 40.760 .500 & 263.533 .500 \\
\hline 24-Juli-2020 & Infaq jumat legi & 1.060 .000 & & 264.593 .500 \\
\hline 31-Juli-2020 & idul adha & 3.246 .500 & & 267.840 .000 \\
\hline 31-Juli-2020 & Infaq jumat pon & 308.000 & & 268.148 .000 \\
\hline 07-Agu-2020 & Infaq jumat kliwon & 265.000 & & 268.413 .000 \\
\hline 14-Agu-2020 & Infaq jumat paing & 988.000 & & 269.401 .000 \\
\hline \multirow[t]{2}{*}{ 21-Agu-2020 } & Infaq jumat wage & 1.565 .000 & & 270.966 .000 \\
\hline & kebersihan p. nur & & 1.000 .000 & 269.966 .000 \\
\hline 28-Agu-2020 & Infaq jumat legi & 7.660 .000 & & 277.626 .000 \\
\hline 04-Sep-2020 & Infaq jumat pon & 649.000 & & 278.275 .000 \\
\hline \multirow[t]{4}{*}{ 11-Sep-2020 } & Infaq jumat kliwon & 3.495 .000 & & 281.770 .000 \\
\hline & tambah daya listrik & & 1750.000 & 280.020 .000 \\
\hline & masuk panitia pembangunan & & 250.000 .000 & 30.020 .000 \\
\hline & masuk panitia & & 27.000 .000 & 3020.000 \\
\hline 18-Sep-2020 & Infaq jumat paing & 6.440 .000 & & 9.460 .000 \\
\hline 25-Sep-2020 & Infaq jumat wage & 1.520 .000 & & 10.980 .000 \\
\hline \multirow[t]{2}{*}{ 02-Okt-2020 } & Infaq jumat manis & 980.000 & & 11.960 .000 \\
\hline & dana tersimpan & & 900.000 & 11.060 .000 \\
\hline 09-Okt-2020 & Infaq jumat pon & 345.000 & & 11.405 .000 \\
\hline $16-O k t-2020$ & Infaq jumat kliwon & 590.000 & & 11.995 .000 \\
\hline 23-Okt-2020 & Infaq jumat paing & 400.000 & & 12.395 .000 \\
\hline \multirow[t]{4}{*}{ 30-Okt-2020 } & Infaq jumat wage & 440.000 & & 12.835 .000 \\
\hline & kompor panci bangunan & & 710.000 & 12.125 .000 \\
\hline & masuk panitia bangunan & & 10.000 .000 & 2.125 .000 \\
\hline & Donatur & 5.510 .000 & & 7.635 .000 \\
\hline 06-Nov-2020 & Infaq jumat manis & 350.000 & & 7.985 .000 \\
\hline \multirow[t]{2}{*}{ 13-Nov-2020 } & Infaq jumat pon & 455.000 & & 8.440 .000 \\
\hline & & & 682.000 & 7.758 .000 \\
\hline \multirow[t]{2}{*}{ 20-Nov-2020 } & Donatur & 355.000 & & 8.113 .000 \\
\hline & Infaq jumat kliwon & 290.000 & & 8.403 .000 \\
\hline \multirow[t]{2}{*}{ 27-Nov-2020 } & Infaq jumat paing & 250.000 & & 8.653 .000 \\
\hline & dana tersimpan & & 200.000 & \\
\hline 04-Des-2020 & Infaq jumat wage & 238.000 & & 8.691 .000 \\
\hline 12-Des-2020 & Infaq jumat manis & 305.000 & & 8.996 .000 \\
\hline 18-Des-2020 & Infaq jumat pon & 510.000 & & 9.506 .000 \\
\hline 25-Des-2020 & Infaq jumat kliwon & 310.000 & & 9.816 .000 \\
\hline
\end{tabular}

Sumber : Dokumentasi Masjid Masjid Baitul Hidayah Puger Jember 2020

\section{PEMBAHASAN}

Menurut ISAK 35, organisasi nonlaba perlu menyusun setidaknya 5 jenis laporan keuangan sebagai berikut: 1). Laporan posisi keuangan atau sering disebut juga neraca. 2). Laporan penghasilan komprehensif. 3). Laporan arus kas. 4). Laporan perubahan ekuitas (modal). 5). Catatan atas laporan keuangan. Berdasarkan analisis data, dapat disimpulkan bahwa Masjid Baitul
Hidayah hanya menyusun laporan secara sederhana dan tidak membuat laporan keuangan sesuai dengan yang ditetapkan oleh ISAK 35. Hal tersebut disebabkan oleh penyusun laporan keuangan yang belum memahami dan mengerti laporan keuangan tentang ISAK 35. Sehingga dapat disimpulkan bahwa laporan keuangan Masjid Baitul Hidayah belum sesuai dengan Interpretasi Standar 


Akuntansi Keuangan karena belum
memenuhi kriteria-kriteria
ditetapkan oleh ISAK 35.

\section{Rekonstruksi Laporan Keuangan Berdasarkan ISAK 35}

Berdasarkan hasil analisis dan pembahasan diatas, maka peneliti mencoba merekonstruksi laporan keuangan Masjid Baitul Hidayah sesuai dengan ISAK 35
1. Laporan Posisi Keuangan

Laporan posisi keuangan terdiri dari dua bagian yaitu aktiva dan pasiva. Adapun bentuk laporan posisi keuangan yang peneliti konstruk sesuai ISAK No. 35 dapat dilihat pada tabel 2.

Tabel 2. Laporan Posisi Keuangan

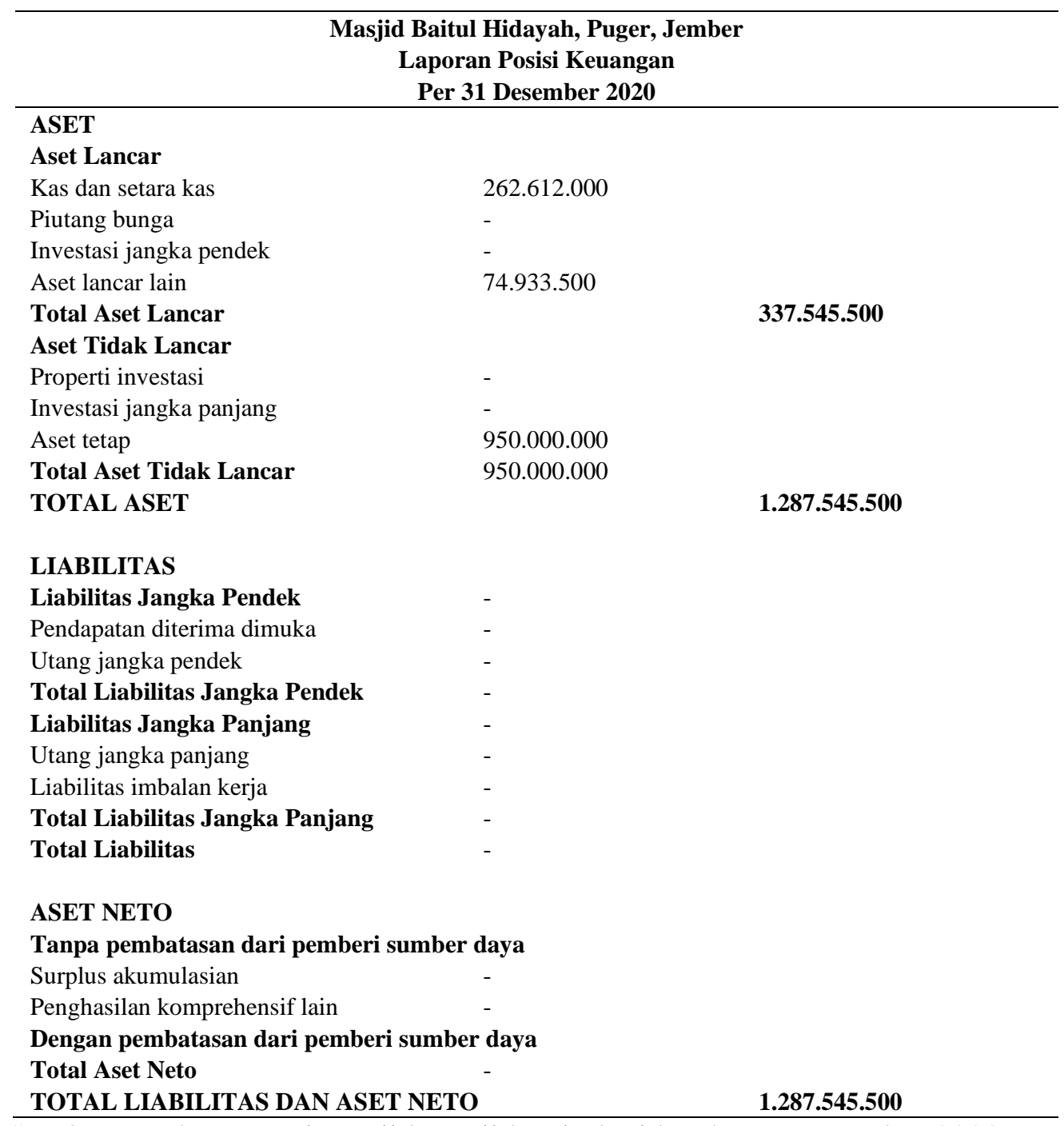

Sumber : Dokumentasi Masjid Masjid Baitul Hidayah Puger Jember 2020 
2. Laporan Penghasilan Komprehensif

Laporan penghasilan komprehensif adalah salah satu laporan keuangan yang mengukur seberapa besar keberhasilan perusahaan dalam periode tertentu.
Adapun bentuk laporan penghasilan komprehensif yang peneliti konstruk sesuai dengan ISAK 35 dapat dilihat pada tabel 3

Tabel 3. Laporan Penghasilan Komprehensif

\begin{tabular}{|c|c|c|}
\hline $\begin{array}{r}\text { Masji } \\
\text { Lapo }\end{array}$ & $\begin{array}{l}\text { I Hidayah, Puger, Jember } \\
\text { nghasilan Komprehensif } \\
1 \text { Desember } 2020\end{array}$ & \\
\hline TANPA PEMBATASAN DARI PI & RI SUMBER DAYA & \\
\hline Pendapatan & & \\
\hline Sumbangan & 262.612 .000 & \\
\hline Jasa layanan & & \\
\hline Penghasil investasi jangka pendek & - & \\
\hline Penghasil investasi jangka panjang & - & \\
\hline Lain-lain & 74.933 .500 & \\
\hline Total Pendapatan & & 337.545.500 \\
\hline Beban & & \\
\hline Gaji, upah & 3.600 .000 & \\
\hline Jasa dan professional & 37.000 .000 & \\
\hline Administrative & - & \\
\hline Depresiasi & - & \\
\hline Bunga & - & \\
\hline Lain-lain & 295.712 .500 & \\
\hline Kerugian akibat kebakaran & - & \\
\hline Total Beban & & 336.312.500 \\
\hline Surplus (Defisit) & - & \\
\hline DENGAN PEMBATASAN DARI & ERI SUMBER DAYA & \\
\hline Pendapatan & & \\
\hline Sumbangan & 262.612 .000 & \\
\hline Penghasil investasi jangka panjang & - & \\
\hline Total pendapatan & & 262.612 .000 \\
\hline Beban & & \\
\hline Kerugian akibat kebakaran & & \\
\hline Surplus (defisit) & & \\
\hline Penghasilan Komprehensif Lain & & \\
\hline Total Penghasilan Komprehensif & & 263.845.000 \\
\hline
\end{tabular}

\section{Laporan Arus Kas}

Tujuan utama laporan arus kas adalah menyajikan informasi mengenai penerimaan dan pengeluaran kas dalam satu periode. Adapun klasifikasi penerimaan dan pengeluaran kas pada laporan arus kas organisasi nonlaba, sama dengan yang ada pada organisasi bisnis, yaitu: arus kas dari aktivitas operasi, aktivitas investasi dan aktivitas pendanaan. Adapun bentuk laporan arus kas yang peneliti konstruk sesuai dengan ISAK 35 terdapat pada tabel 4 . 
Tabel 4. Laporan Arus Kas

\begin{tabular}{|c|c|}
\hline $\begin{array}{c}\text { Masjid Baitul Hidayah, Puger, Jember } \\
\text { Laporan Arus Kas } \\
\text { Per } 31 \text { Desember 2020 } \\
\end{array}$ & \\
\hline AKTIVITAS OPERASI & \\
\hline Kas dari sumbangan & 262.612 .000 \\
\hline Kas dari pendapatan jasa & \\
\hline Bunga yang diterima & \\
\hline Penerimaan lain-lain & 74.933 .500 \\
\hline Bunga yang dibayarkan & \\
\hline Kas yang dibayarkan kepada karyawan & $(40.600 .000)$ \\
\hline Kas neto dari aktivitas operasi & \\
\hline AKTIVITAS INVESTASI & \\
\hline Ganti rugi dan asuransi kebakaran & \\
\hline Pembelian peralatan & $(3.370 .000)$ \\
\hline Penerimaan dari penjualan investasi & \\
\hline Kas neto yang digunakan untuk aktivasi investasi & \\
\hline AKTIVITAS PENDANAAN & \\
\hline $\begin{array}{l}\text { Penerimaan dari sumbangan yang dibatasi untuk investasi dalam dana } \\
\text { abadi (endowment) }\end{array}$ & \\
\hline Investasi bangunan & \\
\hline Aktivitas pendanaan lain : & \\
\hline Bunga dibatasi untuk reinvestasi & \\
\hline Pembayaran liabilitas jangka panjang & \\
\hline Kas neto yang digunakan untuk aktivasi pendanaan & \\
\hline KENAIKAN (PENURUNAN) NETO KAS DAN SETARA KAS & $(290.760 .500)$ \\
\hline KAS DAN SETARA KAS PADA AWAL PERIODE & \\
\hline KAS DAN SETARA KAS PADA AKHIR PERIODE & 2.815.000 \\
\hline
\end{tabular}

\section{KESIMPULAN}

Berdasarkan hasil penelitian dan pembahasan mengenai penerapan ISAK 35 pada Masjid Baitul Hidayah maka diperoleh beberapa simpulan sebagai berikut :

1. Sistem penerimaan Masjid Baitul Hidayah Puger diperoleh dari infaq jumat, infaq idul fitri, infaq idul adha serta infaq dari para donatur.

2. Sistem pengeluaran Masjid Baitul Hidayah Puger masih belum disusun secara lengkap setiap bulannya, seperti pengeluaran rutin untuk biaya air dan listrik dan gaji pengurus kebersihan.

3. Masjid Baitul Hidayah Puger masih belum menerapkan penyusunan laporan keuangan yang sesuai dengan ISAK 35, karena dalam penyusunan dan pembuatan laporan keuangan di Masjid Baitul Hidayah Puger hanya mengacu pada laporan keuangan masjid pada umumnya serta tidak memiliki ketentuan khusus.

4. Pencatatan dan pengelolaan keuangan Masjid Baitul Hidayah Puger masih sederhana yakni masih sebatas pada pencatatan pemasukan dan pengeluaran masjid.

\section{SARAN}

Berdasarkan hasil penelitian dan pembahasan mengenai penerapan ISAK 35 pada Masjid Baitul Hidayah, maka 
peneliti memberikan saran atau rekomendasi bagi pengurus masjid sebagai berikut :

1. Peneliti menyarankan kepada bendahara Masjid Baitul Hidayah agar menyusun laporan keuangan sesuai dengan Interpretasi Standar Akuntansi Keuangan (ISAK 35).

2. Peneliti menyarankan agar bendahara Masjid Baitul Hidayah mengelola dan mencatat pemasukan dan pengeluran setiap bulannya secara lebih rinci agar laporan keuangan lebih lengkap dan meminimalisir kesalahan dalam perhitungan jumlah kas Masjid Baitul Hidayah Puger.

3. Peneliti menyarankan agar pengurus Masjid Baitul Hidayah Puger turut membantu serta melakukan pengecekan rutin yang berkaitan dengan penerimaan dan pengeluaran masjid bersama bendahara masjid.

4. Peneliti menyarankan agar pengurus Masjid Baitul Hidayah Puger mengkoordinasikan untuk membuat fasilitas masjid bagi warga yang dapat membuat investasi jangka panjang sehingga penerimaan Masjid Baitul Hidayah Puger tidak hanya diperoleh dari infaq dan donasi.

\section{DAFTAR PUSTAKA}

Accounting Principles Board. (1970). APB Statement No.4 Basic Concepts and Accounting Principles Underlying Financial Statement of Business Entreprise. AICPA.

American Accounting Association. (1966). A Statement of Basic Accounting Theory: Committee to Prepare a Statement of Basic Accounting Theory. USA: Illinois.

Al-Muqoddam, Faqih A. (2016). Analisis dan Rekonstruksi Laporan Keuangan pada SMA Excellent AlTasini. Artikel Ilmiah Mahasiswa. Jember: Universitas Jember.

Arifin., Zainal. (2014). Pertanggungjawaban Keuangan Pondok Pesantren: Studi Pada Yayasan Nazhatut Thullab. Jurnal Ilmu \& Riset Akuntansi, 3 (11), 5.

Arikunto, Suharsimi. (1986). Prosedur Penelitian Suatu Pendekatan Praktis. Jakarta: Rineka Cipta.

Arikunto, S. 2002. Metodologi Penelitian Suatu Pendekatan Proposal. Jakarta:PT Rineka Cipta.

Bastian, Indra. (2007). Akuntansi Pendidikan. Jakarta: Erlangga.

Bastian, Indra. (2007). Akuntansi Yayasan dan Lembaga Publik. Jakarta: Erlangga.

Bastian, Indra. (2010). Akuntansi Sektor Publik Suatu Pengantar. Jakarta: Erlangga.

Bigliardi, Barbara dan Alberto Ivo Dormio. (2012). The Impact of Organizational Culture on The Job Satisfaction of Knowledge Workers. Emerald, 2 (1), 36-51. 
Creswell, Jhon W. (2016). Research Design Pendekatan Metode Kualitatif, Kuantitatif, dan Campuran. Edisi Empat. Yogyakarta: Pustaka Pelajar.

Dinanti, dan Nugraha. (2018). Pelaporan Keuangan Organisasi Nirlaba. Jurnal Ekonomi, Bisnis, dan Akuntansi (JEBA), 20 (1).

Glynn. (1993). American Accounting Association. Jakarta: Tiga Serangkai.

Gazalbi, Sidi, 1994 , Masjid Pusat Ibadah dan Kebudayaan Islam, Jakarta: Pustaka Al-Husna.

Halim, Abdul. (2009). Akuntansi Sector Publik Akuntansi Keuangan Daerah, Jakarta: Salemba Empat.

Halim, Abdul. (2010). Akuntansi Sektor Publik. Jakarta: Salemba Empat.

Herdiansyah, H. (2014). Metodologi Penelitian Kualitatif. Jakarta: Salemba Empat

Ikatan Akuntan Indonesia. (2013). Standar Akuntansi Keuangan Entitas Tanpa Akuntabilitas Publik (SAK ETAP). Jakarta: Ikatan Akuntan Indonesia.

Ikatan Akuntan Indonesia (IAI). (2018). Penyajian Laporan Keuangan Entitas Berorientasi Nonlaba, DE ISAK 35. Jakarta: DSAK-IAI

Ikatan Akuntan Indonesia (IAI). (2012). Standar Akuntansi Keuangan. Jakarta: Salemba Empat.

Mardiasmo. (2009). Otonomi dan Manajemen Keuangan Daerah. Yogyakarta: Penerbit Andi

Margono, 2004, Metodologi Penelitian Pendidikan, Jakarta : Rineke Cipta.

Moleong, LJ. (2016). Metodologi Penelitian Kualitatif. Bandung: Remaja Rosdakarya Offset.
Mulya, Hadri. (2013). Memahami Akuntansi Dasar. Jakarta: Mitra Wacana Media.

Nordiawan, Deddi. (2009). Akuntansi Pemerintahan. Jakarta: Salemba Empat.

Sadeli, Lili. (2016). Dasar-Dasar Akuntansi. Jakarta: Bumi Aksara.

Salusu, J. (2006). Pengambilan Keputusan Strategik untuk Organisasi Publik dan Organisasi Non Profit. Jakarta: Grasindo.

Setyadin. (2005). Metode Penelitian Kualitatif: Teori dan Praktik. Jakarta: Bumi Aksara.

Sugiono, Arif. (2009). Akuntansi dan Pelaporan Keuangan untuk Bisnis Skala Kecil dan Menengah. Jakarta: Grasindo.

Sugiyono. (2013). Metode Penelitian Kuantitatif, Kualitatif dan Kombinasi. Bandung: Alfabeta.

Sujarweni, V. Wiratna. (2015). Akuntansi Sektor Publik. Yogyakarta: Pustaka Baru Press Yogyakarta.

Undang-Undang Republik Indonesia Nomor 16 Tahun 2001 Tentang Yayasan 
